\title{
Hypercapnia: is it protective in lung injury?
}

\author{
Alexander F Bautista ${ }^{1}$ and Ozan Akca ${ }^{1,2^{*}}$
}

\begin{abstract}
Hypercapnic acidosis has been regarded as a tolerated side effect of protective lung ventilation strategies. Various in vivo and ex vivo animal studies have shown beneficial effects in acute lung injury setting, but some recent work raised concerns about its anti-inflammatory properties. This mini-review article aims to expand the potential clinical spectrum of hypercapnic acidosis in critically ill patients with lung injury. Despite the proven benefits of hypercapnic acidosis, further safety studies including dose-effect, level-and-onset of anti-inflammatory effect, and safe applicability period need to be performed in various models of lung injury in animals and humans to further elucidate its protective role.

Keywords: Hypercapnia, Hypercarbia, Carbon Dioxide, Oxygenation, Acute Lung Injury (ALI), Ventilator Associated Lung Injury (VALI), Pneumonia, Sepsis, Acute Respiratory Distress Syndrome (ARDS), Ventilator-induced

diaphragmatic dysfunction (VIDD)
\end{abstract}

\section{Introduction}

Management of critically ill patients has been continuously evolving. Technological advancement has improved the immediacy and quality of monitoring. Basic and translational researches have changed the approach in medical management from simplistic acid-base approach to much more sophisticated real-time compartmental electrolyte assessments to neurally-adjusted ventilator management. Now, we can follow inhaled-exhaled oxygen and carbon dioxide levels at our bedside patient monitors, and assess blood gas partial pressures as our stat labs.

Hypercapnia with and without acidosis has been observed in critically ill patients for many decades. This observation was either regarded as not beneficial or even harmful mostly due to its $\mathrm{pH}$-related effects and complicated responses in the central nervous system. Recent studies have shown compelling evidence suggesting beneficial effects of hypercapnic acidosis in various different lung injury models in animals and human [1-3]. The majority of basic and clinical work focused on ventilatory strategies with regards to the beneficial effects of moderate hypercapnia. This article aims to discuss the beneficial and potentially harmful effects of permissive hypercapnia in the perspective of critically ill patients with lung injury.

\footnotetext{
* Correspondence: ozan.akca@louisville.edu

${ }^{1}$ Department of Anesthesiology \& Perioperative Medicine, University of Louisville, Louisville, KY 40202, USA

${ }^{2}$ Outcomes ResearchTM Consortium, Cleveland Clinic Foundation, Cleveland, $\mathrm{OH}, \mathrm{USA}$
}

\section{() Biomed Central}

(c) 2013 Bautista and Akca; licensee BioMed Central Ltd. This is an open access article distributed under the terms of the Creative Commons Attribution License (http://creativecommons.org/licenses/by/2.0), which permits unrestricted use, distribution, and reproduction in any medium, provided the original work is properly cited.
Effects on heart, lungs, \& oxygenation Carbon dioxide \& cellular compartments

Carbon dioxide $\left(\mathrm{CO}_{2}\right)$ is a by-product of cellular respiration. It plays a major role in the acid-base balance essential for intracellular and extracellular hemostasis. It has moderate water solubility. The reaction of dissolved $\mathrm{CO}_{2}$ and water will yield carbonic acid, with the enzyme carbonic anhydrase reversibly catalyzing the dissociation of carbonic acid:

$$
\mathrm{H}_{2} \mathrm{O}+\mathrm{CO}_{2} \rightarrow \mathrm{H}_{2} \mathrm{CO}_{3} \rightarrow \mathrm{H}^{+}+\mathrm{HCO}_{3}{ }^{-} \rightarrow \mathrm{H}^{+}+\mathrm{CO}_{3}{ }^{2-}
$$

Carbon dioxide moves across the intracellular compartment via a concentration gradient. It is actively removed through exhalation by the respiratory system. Changes in partial pressure of $\mathrm{CO}_{2}$ will effect changes in hydrogen ion concentration.

\section{Clinically established levels of carbon dioxide}

The normal carbon dioxide tension is considered to be within the range of $35-45 \mathrm{mmHg}$. Hypercapnia is generally defined as carbon dioxide partial pressure of higher than $45 \mathrm{mmHg}$. Mild hypercapnia is noted to having $\mathrm{CO}_{2}$ partial pressure of up to $50 \mathrm{mmHg}$ [4,5]. Jung et. al, defined moderate hypercapnia as $\mathrm{PaCO}_{2}$ levels between the range of 55 to $70 \mathrm{mmHg}$ [3]. Levels higher than $75 \mathrm{mmHg}$ are generally regarded as severe hypercapnia [6,7]. When considering these arbitrary levels of hypercapnia, it is 
important to emphasize that severity leveling of hypercapnia alone without a corresponding $\mathrm{pH}$ value, which is also affected by metabolic changes, may not represent the expected frame of clinical effects.

Since there is an overlap between the partial $\mathrm{CO}_{2}$ ranges presented in most of the clinical studies cited in this article, we are alluding to mild-to-moderate hypercapnia for discussion purposes. Significance and contribution of acidosis levels are not equal between the studies cited. Therefore, we tried to provide the contribution of acidosis for each listed study.

\section{Respiratory effects of hypercapnia}

The main physiologic effect of increased $\mathrm{CO}_{2}$ in patients would result in a right-ward shift of the oxygen dissociation curve which, in effect, improves unloading of oxygen at the tissue level. In a canine model, arterial hypercapnia produced a gradual and significant increase in oxygen carrying capacity [8]. An increase in intracellular $\mathrm{H}^{+}$led to decrease in pulmonary vascular resistance [9] abolishing hypoxic pulmonary vasoconstriction, reduction in intrapulmonary shunting and improvement of ventilationperfusion mismatch [10]. Hypercapnia also attenuates fluid dynamics in pulmonary vasculature, which would keep the diffusion distance between the pulmonary capillary and the alveoli short, thereby preserving optimal gas exchange and preventing edema formation [11]. Although hypercapnia may notably increase pulmonary vascular resistance, due to its overall effects in decreasing pro-inflammatory response and fluid dynamics in the pulmonary vasculature, the overall effect may not always appear as increased pulmonary vascular resistance.

\section{Effects on hemodynamics and oxygenation}

Hypercapnia increases cardiac output, oxygen carrying capacity, mixed venous oxygen, and also peripheral tissue oxygenation [12-15]. The increases in cerebral tissue oxygenation can be observed to some extent even when cardiac output was kept constant [16] which can possibly be explained by the relationship of oxygen supply and demand. Increase in cardiac output appears to be related to inotropic effect through $\beta$-adrenergic receptors, and hypercapnia-induced sympathetic activation and catecholamines $[17,18]$. Hypercapnia decreases systemic vascular resistance, [19] which may further support tissue perfusion especially when intravascular volume status is maintained.

Cardiac index increases by about $10-15 \%$ for each 10 $\mathrm{mmHg}$ increments in arterial carbon dioxide tension within a range of 30 to $50 \mathrm{mmHg}$ [12,20]. Additionally, the rightward shift of the oxyhemoglobin dissociation curve and decreases in systemic vascular resistance increase oxygen availability to the peripheral tissue [20]. Ratnaraj et al. showed that increasing end-tidal carbon dioxide tension from 30 to $50 \mathrm{mmHg}$ improved both subcutaneous tissue oxygen tension by $\sim 23 \%$, and intramural oxygenation in large and small intestine by 16 -to- $45 \%$ under general anesthesia in a pig model [21]. Fleischmann et al. showed that even under high inspired oxygen concentration of 0.80 in colorectal surgery patients who were assigned to mild hypercapnia (ET $\mathrm{PCO}_{2}$ of $50 \mathrm{mmHg}$ ), subcutaneous tissue oxygenation increased by $38 \%$ and colon intramural oxygenation increased by about $100 \%$ compared to the patients who were assigned to normocapnia (ET $\mathrm{PCO}_{2}$ of $35 \mathrm{mmHg}$ ) [4]. More recently, Schwartges et al. elegantly showed that incremental levels of carbon dioxide increased cardiac output and systemic oxygen delivery in dogs, which was measured as dissolved oxygen and gastric mucosal oxygen saturation [22].

In spite of the positive oxygenation and perfusion effects by hypercapnia as described above, it should also be noted that myocardial depression due to overwhelming effects on inotropy and catecholamines may develop at $\mathrm{CO}_{2}$ concentrations greater than $10-15 \%$ (i.e., $\mathrm{PaCO}_{2}>75 \mathrm{mmHg}$ ) $[23,24]$ regardless of compensatory mechanisms to correct acidosis.

\section{Hypercapnia \& ventilator-associated lung injury (VALI)}

Mechanical stress associated with overstretching alveoli can cause lung injury. This is clearly evident with the use of higher tidal volumes and increased transpulmonary pressure during mechanical ventilation resulting in ventilator associated lung injury (VALI). Experimental studies have shown that lung injury markers such as the presence of pulmonary edema, hyaline membranes, epithelial injury, filtration coefficient [25] and lymphatic flow are increased with higher tidal volumes [26]. To minimize this insult, it has been advocated to utilize smaller tidal volumes i.e. $7 \mathrm{ml} / \mathrm{kg}$ or less [27] and to limit the plateau airway pressure to $35 \mathrm{~cm} \mathrm{H}_{2} \mathrm{O}$ or lower [28]. This in effect will cause a slow increase in $\mathrm{PaCO}_{2}$ hence implementation of permissive hypercapnia if there is no adjustment in respiratory rate [2]. In a prospective randomized animal study with moderate to severe ventilation-induced lung injury, hypercapnic acidosis significantly reduced stretchinduced lung injury and resulted in higher arterial $\mathrm{PO}_{2}$ compared to normocapnia. Moreover, it also showed reduction in lung permeability as evidenced by bronchoalveolar protein concentrations and attenuated the decrease in static lung compliance in comparison with the normocapnia group [29]. This study confirms the growing body of evidence that suggests hypercapnic acidosis involvement in the inhibition of nuclear factor kappa-B (NF-KB) that regulates genes central to lung injury, inflammation and repair.

In a large, randomized-controlled trial from the ARDS Network, Kregenow and colleagues demonstrated that permissive hypercapnia ( $\mathrm{pH}<7.35$ and $\mathrm{PCO} 2>45 \mathrm{mmHg}$ ) reduced 28-day mortality in patients with acute lung injury 
who were ventilated with $12 \mathrm{~mL} / \mathrm{kg}$ predicted body weight tidal volume [30]. This is in part due the ability of hypercapnic acidosis to attenuate physiologic and histological indices of lung injury induced by very high levels of lung stretch, [31] but not that due to the collapse and re-expansion of atelectatic lung [1]. Laffey and Kavanagh also stated that the combination of reduction of lung stretch and permissive hypercapnia is additive in preventing VALI [32].

Hypercapnia \& ventilator-induced diaphragmatic injury (VIDD) Ventilator-induced diaphragmatic dysfunction (VIDD) is another complication of prolonged controlled ventilation. It may progress to diaphragmatic muscle atrophy and result in long-term dependence on mechanical ventilation [33]. Diaphragmatic muscle weakening can be explained by proteolysis, apoptosis and oxidative stress, [34] and it appears to be directly proportional to duration of mechanical ventilation; [35] anti-oxidant and anti-inflammatory agents such as steroids may attenuate the process [36,37].

Recently, Jung et al. reported that after 72 hours of controlled mechanical ventilation, diaphragm contractions to maximal stimulus were preserved in hypercapnic animals compared to a $25 \%$ decrease in the normocapnic ventilated animals [38]. Controlling lung injury, preventing diaphragmatic dysfunction, and altering exaggerated pro-inflammatory responses may suggest an important potential role for mild-to-moderate hypercapnia and hypercapnic acidosis in acutely developing systemic inflammatory processes [39].

\section{Hypercapnia in acute lung injury (ALI) and acute respiratory distress syndrome (ARDS)}

The causes of ALI and ARDS are varied, however, the mainstay in the management of both disease processes is mechanical ventilation, which can by itself further result in VALI as described above. Hence, protective ventilator strategy with permissive hypercapnia has been studied both in human and animal models. Ischemiareperfusion injury is highly associated with the development of ALI. Shibata et al. reported that hypercapnic acidosis inhibits xanthine oxidase, and therefore prevents an increase in capillary permeability, attenuates free-radical-induced lung injury, and possibly prevents apoptosis [40]. Other mechanisms by which hypercapnic acidosis provide protection include attenuation of key etiologic factors that lead to ALI, reduction of physical lung damage, inhibition of key aspects of the inflammatory response and direct protection of systemic organs [41]. As mentioned above, the data published by the ARDS Network and others have shown that hypercapnic acidosis in this subset of patients had a reduced mortality $[27,28,30]$.

\section{Hypercapnia, pneumonia \& sepsis}

Pneumonia and sepsis are the leading causes of increased morbidity in critically ill patients [42]. Hypercapnic acidosis has shown to depress immune function through various mechanisms via macrophage suppression, inhibition of phagocytic function of neutrophils and cytokine signaling $[43,44]$. However, most of these data reported in animal studies and in vitro models. Curley et al. stated that hypercapnic acidosis inhibits the activation of NF-KB, [29] which is responsible for activation and regulation of proinflammatory and repair processes suggesting the reduction of pulmonary epithelial wound healing [45].

Such poor healing phenomenon was demonstrated in in vitro studies using human bronchial epithelial cells exposed to hypercapnia at neutral $\mathrm{pH}$ environment [46]. Despite this mechanistic effect of hypercapnia on the immune system, hypercapnic acidosis has been shown to improve physiologic indices of injury in the setting of acute bacterial pneumonia [47]. Ni Chonghaile et. al. demonstrated that hypercapnic acidosis attenuated the increase in airway pressure and the decrease in both lung compliance and arterial oxygenation in their animal model via a neutrophil-independent mechanism [47]. In a follow-up study, using their established pneumonia model, they showed that the protective effects of hypercapnic acidosis are further enhanced with the use of appropriate antibiotic therapy [48]. On the contrary, in prolonged untreated pneumonia animal model, hypercapnic acidosis appeared to worsen lung indices in terms of static compliance and arterial oxygenation, [49] and was associated with higher bacterial count and increased mortality [50].

With regard to systemic sepsis, animal models with hypercapnic acidosis demonstrated improvement in hemodynamic parameters, preserved central venous oxygen saturation, slowed the development of hypotension, and attenuated the associated increase in lactic acid concentration when compared to normocapnia [51-53]. Additionally, hypercapnia may have some minimal effect in preventing other infection such as surgical site infections [54]. The clinical implication of hypercapnia in effect is also dependent on the stage of the infection, i.e. early or late in the course of the disease process; and also the primary site of infection, may it be pulmonary or systemic source.

\section{Summary}

In conclusion, moderate hypercapnia may play a protective role and may be an integral part of ventilatory management of critically ill patients with VALI, VIDD, ALI and ARDS. Regarding its role in immunomodulation, it may be protective in the setting of acute pneumonia and sepsis, provided adequate antibiotic coverage has been instituted in a timely fashion. However, it should be noted that moderate hypercapnia may worsen the injury 
in prolonged, undiagnosed, untreated pneumonia. Further clinical trials in animals, healthy human subjects, and patients are needed to further assess the safety of hypercapnia, to find the optimum dosing and timing, and finally to elucidate its overall protective role.

\section{Competing interests}

The authors and institution have no conflict of interests. They have no financial or personal relationships with other people or organization that could inappropriately influence their action.

\section{Authors' contributions}

$\mathrm{OA}$ and AFB conceptualized the idea and wrote the manuscript. Both authors have read and approved the final manuscript.

Received: 2 August 2013 Accepted: 5 November 2013

Published: 11 November 2013

\section{References}

1. O'Croinin D, Ni Chonghaile M, Higgins B, Laffey JG: Bench-to-bedside review: Permissive hypercapnia. Crit Care 2005, 9(1):51-59.

2. Rogovik A, Goldman R: Permissive hypercapnia. Emerg Med Clin North Am 2008, 26(4):941-952. viii-ix.

3. Jung B, Sebbane M, Goff CL, Rossel N, Chanques G, Futier E, Constantin JM, Matecki S, Jaber S: Moderate and prolonged hypercapnic acidosis may protect against ventilator-induced diaphragmatic dysfunction in healthy piglet: an in vivo study. Crit Care 2013, 17(1):R15.

4. Fleischmann E, Herbst F, Kugener A, Kabon B, Niedermayr M, Sessler DI, Kurz A: Mild hypercapnia increases subcutaneous and colonic oxygen tension in patients given $80 \%$ inspired oxygen during abdominal surgery. Anesthesiology 2006, 104(5):944-949.

5. Hager H, Reddy D, Mandadi G, Pulley D, Eagon JC, Sessler DI, Kurz A Hypercapnia improves tissue oxygenation in morbidly obese surgical patients. Anesth Analg 2006, 103(3):677-681.

6. Glatte HA Jr, Motsay GJ, Welch BE: Carbon dioxide tolerance studies. SAMTR-67-77. Tech Rep SAM-TR 1967:1-22.

7. Glatte HA Jr, Welch BE: Carbon dioxide tolerance: a review. Aeromed Rev 1967, 5:1-28.

8. Torbati D, Mangino MJ, Garcia E, Estrada M, Totapally BR, Wolfsdorf J: Acute hypercapnia increases the oxygen-carrying capacity of the blood in ventilated dogs. Crit Care Med 1998, 26(11):1863-1867.

9. Kantores C, McNamara PJ, Teixeira L, Engelberts D, Murthy P, Kavanagh BP, Jankov RP: Therapeutic hypercapnia prevents chronic hypoxia-induced pulmonary hypertension in the newborn rat. Am J Physiol Lung Cell Mol Physiol 2006, 291(5):L912-922.

10. Swenson ER, Robertson HT, Hlastala MP: Effects of inspired carbon dioxide on ventilation-perfusion matching in normoxia, hypoxia, and hyperoxia. Am J Respir Crit Care Med 1994, 149(6):1563-1569.

11. Vengust M: Hypercapnic respiratory acidosis: a protective or harmful strategy for critically ill newborn foals? Can J Vet Res 2012, 76(4):275-280

12. Akça O, Doufas A, Morioka N, Iscoe S, Fisher J, Sessler D: Hypercapnia Improves Tissue Oxygenation. Anesthesiology 2002, 97:801-806.

13. Gayan-Ramirez G, Testelmans D, Maes K, Racz GZ, Cadot P, Zador E, Wuytack F, Decramer M: Intermittent spontaneous breathing protects the rat diaphragm from mechanical ventilation effects. Crit Care Med 2005, 33(12):2804-2809.

14. Ali S, Hahn H, Jacobsohn E, DeWet C, Avidan M: Therapeutic effects of carbon dioxide administration following cardiac surgery. In American Society of Anesthesiologists (ASA) Annual Meeting: October 11-15, 2003. San Francisco, CA: Lippincott Williams \& Wilkins; 2003:A-431.

15. Akça O, Liem E, Suleman M-I, Doufas A, Galandiuk S, Sessler D: The effect of intraoperative end-tidal carbon dioxide partial pressure on tissue oxygenation. Anaesthesia 2003, 58(6):536-542

16. Akca O, Sessler DI, Delong D, Keijner R, Ganzel B, Doufas AG: Tissue oxygenation response to mild hypercapnia during cardiopulmonary bypass with constant pump output. Br J Anaesth 2006, 96(6):708-714.

17. Blackburn JP, Conway CM, Leigh JM, Lindop MJ, Reitan JA, Weaver PC: Myocardial carbon dioxide response curves. Br J Anaesth 1970, 42(6):559.
18. Blackburn JP, Conway CM, Leigh JM, Lindop MJ, Reitan JA: Pa CO2 and the pre-ejection period: the pa $\mathrm{CO} 2$ inotropy response curve. Anesthesiology 1972, 37(3):268-276.

19. Walley KR, Lewis TH, Wood LD: Acute respiratory acidosis decreases left ventricular contractility but increases cardiac output in dogs. Circ Res 1990, 67(3):628-635.

20. Mas A, Saura P, Joseph D, Blanch L, Baigorri F, Artigas A, Fernandez R: Effects of acute moderate changes in $\mathrm{PaCO} 2$ on global hemodynamics and gastric perfusion. Crit Care Med 2000, 28(2):360-365.

21. Ratnaraj J, Kabon B, Talcott MR, Sessler DI, Kurz A: Supplemental oxygen and carbon dioxide each increase subcutaneous and intestinal intramural oxygenation. Anesth Analg 2004, 99(1):207-211.

22. Schwartges I, Schwarte LA, Fournell A, Scheeren TW, Picker O: Hypercapnia induces a concentration-dependent increase in gastric mucosal oxygenation in dogs. Intensive Care Med 2008, 34(10):1898-1906.

23. Monroe R, French G, Whittenberger J: Effect of hypocapnia and hypercapnia on myocardial contractility. Am J Physiol 1960, 199:1121-1124.

24. Andersen M, Mouritzen C: Effect of acute respiratory and metabolic acidosis on cardiac output and peripheral resistance. Ann Surg 1966, 63(2):161-168.

25. Peevy KJ, Hernandez LA, Moise AA, Parker JC: Barotrauma and microvascular injury in lungs of nonadult rabbits: effect of ventilation pattern. Crit Care Med 1990, 18(6):634-637.

26. Parker JC, Hernandez LA, Peevy KJ: Mechanisms of ventilator-induced lung injury. Crit Care Med 1993, 21(1):131-143.

27. Petrucci N, lacovelli W: Lung protective ventilation strategy for the acute respiratory distress syndrome. Cochrane Database Syst Rev 2007, 3. CD003844.

28. Network TARDS: Ventilation with lower tidal volumes as compared with traditional tidal volumes for acute lung injury and the acute respiratory distress syndrome. N Engl J Med 2000, 342:1301-1308.

29. Contreras M, Ansari B, Curley G, Higgins BD, Hassett P, O'Toole D, Laffey JG: Hypercapnic acidosis attenuates ventilation-induced lung injury by a nuclear factor-kappaB-dependent mechanism. Crit Care Med 2012, 40(9):2622-2630.

30. Kregenow DA, Rubenfeld GD, Hudson LD, Swenson ER: Hypercapnic acidosis and mortality in acute lung injury. Crit Care Med 2006, 34(1):1-7.

31. Sinclair SE, Kregenow DA, Lamm WJ, Starr IR, Chi EY, Hlastala MP: Hypercapnic acidosis is protective in an in vivo model of ventilatorinduced lung injury. Am J Respir Crit Care Med 2002, 166(3):403-408.

32. Laffey JG, Kavanagh BP: Biological effects of hypercapnia. Intensive Care Med 2000, 26(1):133-138.

33. Jaber S, Jung B, Matecki S, Petrof BJ: Clinical review: ventilator-induced diaphragmatic dysfunction-human studies confirm animal model findings. Crit Care 2011, 15(2):206. doi: 10.1186/cc10023.

34. Petrof BJ, Jaber S, Matecki S: Ventilator-induced diaphragmatic dysfunction. Curr Opin Crit Care 2010, 16(1):19-25. doi: 10.1097/ MCC.0b013e328334b166.

35. Sassoon CS: Ventilator-associated diaphragmatic dysfunction. Am J Respir Crit Care Med 2002, 166(8):1017-1018.

36. McClung JM, Kavazis AN, Whidden MA, DeRuisseau KC, Falk DJ, Criswell DS, Powers SK: Antioxidant administration attenuates mechanical ventilationinduced rat diaphragm muscle atrophy independent of protein kinase $B$ (PKB Akt) signalling. J Physiol 2007, 585(Pt 1):203-215.

37. Maes K, Testelmans D, Cadot P, Deruisseau K, Powers SK, Decramer M, Gayan-Ramirez G: Effects of acute administration of corticosteroids during mechanical ventilation on rat diaphragm. Am J Respir Crit Care Med 2008, 178(12):1219-1226.

38. Jung B, Sebbane M, Goff CL, Rossel N, Chanques G, Futier E, Constantin JM, Matecki S, Jaber S: Moderate and prolonged hypercapnic acidosis may protect against ventilator-induced diaphragmatic dysfunction in healthy piglet: an in vivo study. Crit Care 2013, 17(1):R15. Epub ahead of print.

39. Akca O, Bautista A: Hypercapnia and ventilator-induced diaphragmatic dysfunction. Crit Care 2013, 17(2):129.

40. Shibata K, Cregg N, Engelberts D, Takeuchi A, Fedorko L, Kavanagh BP: Hypercapnic acidosis may attenuate acute lung injury by inhibition of endogenous xanthine oxidase. Am J Respir Crit Care Med 1998, 158(5 Pt 1):1578-1584.

41. Laffey JG, O'Croinin D, McLoughlin P, Kavanagh BP: Permissive hypercapnia-role in protective lung ventilatory strategies. Intensive Care Med 2004, 30(3):347-356. 
42. Lagu T, Rothberg MB, Shieh MS, Pekow PS, Steingrub JS, Lindenauer PK: Hospitalizations, costs, and outcomes of severe sepsis in the United States 2003 to 2007. Crit Care Med 2012, 40(3):754-761. doi: 10.1097/ CCM.0b013e318232db65.

43. Wang N, Gates KL, Trejo H, Favoreto S Jr, Schleimer RP, Sznajder Jl, Beitel GJ, Sporn PH: Elevated $\mathrm{CO} 2$ selectively inhibits interleukin-6 and tumor necrosis factor expression and decreases phagocytosis in the macrophage. FASEB J 2010, 24(7):2178-2190.

44. Coakley RJ, Taggart C, Greene C, McElvaney NG, O'Neill SJ: Ambient pCO2 modulates intracellular $\mathrm{pH}$, intracellular oxidant generation, and interleukin-8 secretion in human neutrophils. J Leukoc Biol 2002, 71(4):603-610.

45. Curley G, Hayes M, Laffey JG: Can 'permissive' hypercapnia modulate the severity of sepsis-induced ALI/ARDS? Crit Care 2011, 15(2):212.

46. O'Toole D, Hassett P, Contreras M, Higgins BD, McKeown ST, McAuley DF, O'Brien T, Laffey JG: Hypercapnic acidosis attenuates pulmonary epithelial wound repair by an NF-kappaB dependent mechanism. Thorax 2009, 64(11):976-982.

47. Ni Chonghaile M, Higgins BD, Costello JF, Laffey JG: Hypercapnic acidosis attenuates severe acute bacterial pneumonia-induced lung injury by a neutrophil-independent mechanism. Crit Care Med 2008, 36(12):3135-3144.

48. Chonghaile MN, Higgins BD, Costello J, Laffey JG: Hypercapnic acidosis attenuates lung injury induced by established bacterial pneumonia. Anesthesiology 2008, 109(5):837-848.

49. O'Croinin DF, Nichol AD, Hopkins N, Boylan J, O'Brien S, O'Connor C, Laffey JG, McLoughlin P: Sustained hypercapnic acidosis during pulmonary infection increases bacterial load and worsens lung injury. Crit Care Med 2008, 36(7):2128-2135.

50. Helenius IT, Krupinski T, Turnbull DW, Gruenbaum Y, Silverman N, Johnson EA, Sporn PH, Sznajder II, Beitel GJ: Elevated CO2 suppresses specific Drosophila innate immune responses and resistance to bacterial infection. Proc Natl Acad Sci U S A 2009, 106(44):18710-18715.

51. Higgins BD, Costello J, Contreras M, Hassett P, D OT, Laffey JG: Differential effects of buffered hypercapnia versus hypercapnic acidosis on shock and lung injury induced by systemic sepsis. Anesthesiology 2009, 111(6):1317-1326.

52. Costello J, Higgins B, Contreras M, Chonghaile MN, Hassett P, O'Toole D, Laffey JG: Hypercapnic acidosis attenuates shock and lung injury in early and prolonged systemic sepsis. Crit Care Med 2009, 37(8):2412-2420.

53. Wang Z, Su F, Bruhn A, Yang X, Vincent JL: Acute hypercapnia improves indices of tissue oxygenation more than dobutamine in septic shock. Am J Respir Crit Care Med 2008, 177(2):178-183.

54. Akca O, Kurz A, Fleischmann E, Buggy D, Herbst F, Stocchi L, Galandiuk S, Iscoe S, Fisher J, Apfel CC, et al: Hypercapnia and surgical site infection: a randomized trial. Br J Anaesth 2013, 111(5):759-767.

\section{Submit your next manuscript to BioMed Central and take full advantage of:}

- Convenient online submission

- Thorough peer review

- No space constraints or color figure charges

- Immediate publication on acceptance

- Inclusion in PubMed, CAS, Scopus and Google Scholar

- Research which is freely available for redistribution

Submit your manuscript at www.biomedcentral.com/submit 